\title{
CARP interacts with titin at a unique helical N2A sequence and at the domain Ig81 to form a structured complex
}

\author{
Tiankun Zhou ${ }^{1,2, *}$, Jennifer R. Fleming ${ }^{1,2, *}$, Barbara Franke ${ }^{1}$, Julius Bogomolovas ${ }^{3}$, Igor Barsukov ${ }^{2}$, \\ Daniel J. Rigden ${ }^{2}$, Siegfried Labeit ${ }^{3}$ and Olga Mayans ${ }^{1,2}$ \\ 1 Department of Biology, University of Konstanz, Germany \\ 2 Institute of Integrative Biology, University of Liverpool, UK \\ 3 Department of Integrative Pathophysiology, Medical Faculty Mannheim, University of Heidelberg, Mannheim, Germany
}

*These authors contributed equally to the work

\begin{abstract}
The cardiac ankyrin repeat protein (CARP) is up-regulated in the myocardium during cardiovascular disease and in response to mechanical or toxic stress. Stress-induced CARP interacts with the N2A spring region of the titin filament to modulate muscle compliance. We characterize the interaction between CARP and titin-N2A and show that the binding site in titin spans the dual domain UN2A-Ig81. We find that the unique sequence UN2A is not structurally disordered, but that it has a stable, elongated $\alpha$-helical fold that possibly acts as a constant force spring. Our findings portray CARP/titinN2A as a structured node and help to rationalize the molecular basis of CARP mechanosensing in the sarcomeric I-band.
\end{abstract}

Keywords: circular dichroism; recombinant proteins; SEC-MALLS; smallangle X-ray scattering; X-ray crystallography
The muscle protein titin ( $>38000$ residues) is a central player in cardiovascular health and disease [1,2]. Titin contributes to maintain the mechanical properties of muscle and to the functional integration of sarcomere signaling. Two important signaling hubs have been identified in the elastic I-band region of titin: the N2A and the $\mathrm{N} 2 \mathrm{~B}$ elements $[1,3,4]$. N2A is functionally essential and is present in both cardiac and skeletal isoforms of titin, whereas $\mathrm{N} 2 \mathrm{~B}$ is found exclusively in the heart. N2A interacts with the calcium-dependent proteases, calpains [5,6], and with MARPs, a family of muscle-specific ankyrin repeat proteins [7,8]. The importance of the $\mathrm{N} 2 \mathrm{~A}$ element is demonstrated by a deletion that truncates domain Ig83 and which causes severe muscular degeneration in $m d m$ (muscular dystrophy and myositis)-mutant mice [9]. Here, calpain-3 binding is abolished [5] and MARP binding is abnormally up-regulated, pointing to the central role of $\mathrm{N} 2 \mathrm{~A}$ in modulating both signaling pathways [10].

The MARP gene family comprises three members: the cardiac-specific CARP/Ankrd1, Ankrd2/Arpp, and the diabetes-associated DARP [7]. While MARPs are not generally essential [11], the CARP isoform is particularly relevant as its expression in the heart is consistently up-regulated during heart failure. Initially, CARP was identified as a nuclear regulator of

\footnotetext{
Abbreviation

$A R$, ankyrin repeats; BiYFP, bimolecular fluorescence complementation of yellow fluorescent protein; CARP, cardiac ankyrin repeat protein; $C D$, circular dichroism; DRI, differential refractive index; DSF, differential scanning fluorimetry; MM, molecular mass; NRMSD, normalized root-mean-square deviation; $R_{\mathrm{g}}$, radius of gyration; SAXS, small-angle X-ray scattering; SEC-MALLS, size exclusion chromatography with multiangle laser light scattering; TEV, tobacco etch virus.
} 
the Nkx2.5 pathway $[12,13]$, but subsequent studies also demonstrated extranuclear roles, including a stress-induced targeting of the sarcomere, e.g., in response to mechanical overload [7,14]). CARP is also deregulated in heart failure of diverse origins, including dilated cardiomyopathy, hypertrophic cardiomyopathy, and arrhythmogenic right ventricular cardiomyopathy [1518]. In all cases, its presence correlates with disease progression allegedly as a result of playing a role in disease resistance [19]. Thus, CARP is currently viewed as a stress response factor in the heart, where it appears to increase the resistance of cardiomyocytes to apoptosis, protecting the myocardium against damage.

Upon its stress induction, CARP localizes largely to the sarcomeric I-band, where it interacts with titin N2A [7,11]. As the N2A segment is an elastic spring of titin, its interaction with CARP is thought to modulate muscle compliance. Such modulation might be induced partly by a direct alteration of the stretch response of the spring and partly by the protection of N2A against phosphorylation. N2A is phosphorylated by PKA (or PKG), which increases titin's compliance and reduces passive force in the sarcomere [8,20]. Accordingly, myofibrils from knockout mice of CARP, MARP, and DARP show high levels of phosphorylation and become more compliant as the length of the myofibril increases [21], supporting the view that CARP can control the stiffness of titin by blocking N2A phosphorylation. In addition, it has been hypothesized that CARP acts as a cross-linker of titin filaments, providing stretch resilience to the sarcomere [8]. As stretch overload causes apoptosis of cardiomyocytes, leading to heart failure [22], it is speculated that the CARP : N2A interaction might have an antiapoptotic role in muscle.

At the molecular level, CARP consists of N- and Cterminal domains. The $\mathrm{N}$-terminal fraction $(\sim 115$ residues) is predicted as structurally disordered [8]. However, it contains a short coiled-coil motif that induces the antiparallel dimerization of CARP, according to bimolecular fluorescence complementation of yellow fluorescent protein (BiYFP) and pull-down assays $[8,23]$. CARP's C-terminal region ( 200 residues $)$ is predicted to fold into various ankyrin repeats (AR; 4-6 repeats variably predicted; [8,24,25]). This AR domain has been shown to bind titin N2A [8]. The latter consists of a unique sequence and four Ig domains (Fig. 1). Data from yeast two-hybrid screens indicated that the elastic unique sequence between $\operatorname{Ig} 80$ and $\operatorname{Ig} 81$, UN2A, is the site of interaction with CARP [7].

Despite the importance of CARP-N2A signaling in heart physiology, little is known about the molecular basis of this interaction. Here, we characterize biophysically the CARP : N2A complex and its

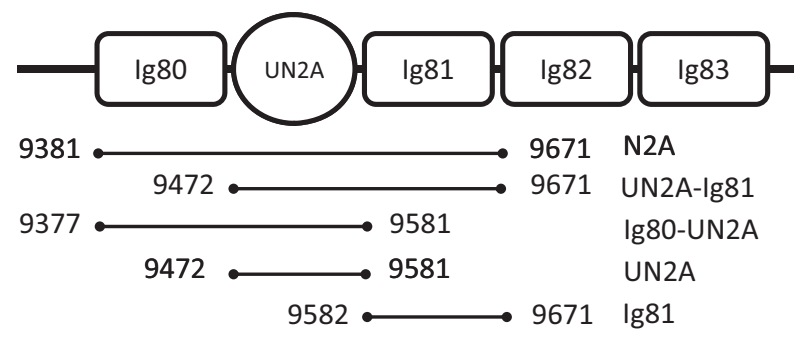

Fig. 1. Domain composition of the N2A region of titin. The composition of the various constructs used in this study is shown.

components and provide an experimental foundation that can support future studies on the function of this association.

\section{Methods}

\section{Expression clones}

CARP ${ }^{106-319}$ (UniProtKB Q15327) and the domain variants of titin N2A (UniProtKB Q8WZ42; Fig. 1) were cloned into the pET-trxla vector. This vector fuses a His $6^{-}$ tag, a thioredoxin domain, and a tobacco etch virus (TEV) protease cleavage site to the $\mathrm{N}$ terminus of the inserted gene. All plasmids were confirmed by sequencing.

\section{Recombinant protein production}

Proteins were expressed in E. coli Rosetta (DE3; Merck Millipore, Billerica, MA, USA) cultivated in Luria-Bertani media supplemented with $25 \mu \mathrm{g} \mathrm{mL}^{-1}$ kanamycin and $34 \mu \mathrm{g} \mathrm{mL}^{-1}$ chloramphenicol at $37{ }^{\circ} \mathrm{C}$ until $\mathrm{OD}_{600}=0.6$. Protein expression was induced with $0.5 \mathrm{~mm}$ isopropyl- $\beta$-D-1-thiogalactopyranoside and cultures grown further overnight at $18{ }^{\circ} \mathrm{C}$. Cells were harvested by centrifugation and lyzed with a pressure homogenizer in $25 \mathrm{~mm}$ HEPES pH7.5, $300 \mathrm{~mm} \mathrm{NaCl}$ in the presence of an EDTA-free protease inhibitor cocktail (Roche Applied Science, Penzberg, Bavaria, Germany) and $1 \mathrm{mg}$ DNAse (Sigma-Aldrich, St. Louis, MO, USA). The lysate was clarified by centrifugation. The purification of all proteins from supernatants followed $\mathrm{Ni}^{2+}$-NTA affinity chromatography, tag removal by TEV protease digestion, reverse affinity chromatography, and size exclusion chromatography - the latter in $25 \mathrm{~mm}$ HEPES pH7.5, $100 \mathrm{~mm}$ $\mathrm{NaCl}$. Purified samples were stored at $4{ }^{\circ} \mathrm{C}$ until further use.

CARP : titin complexes were produced by mixing purified samples at $1: 1$ molar ratio in $25 \mathrm{~mm}$ HEPES pH7.5, $100 \mathrm{~mm} \mathrm{NaCl}$.

\section{Circular dichroism spectroscopy}

Circular dichroism (CD) spectra were recorded on an 1100 CD spectrometer (JASCO, Easton, MD, USA). Samples 
were studied in $20 \mathrm{~mm}$ sodium phosphate $\mathrm{pH} 7.5$ at a concentration of $0.18 \mathrm{mg} \mathrm{mL}^{-1}$ for CARP $\mathrm{CP}^{106-319}$ and $0.29 \mathrm{mg} \mathrm{mL}^{-1}$ for UN2A. The spectral range was $\lambda=185$ $260 \mathrm{~nm}$ and a $1 \mathrm{~mm}$ cell (cell type 110-QS; HELLMA, Müllheim, Germany) was used. Spectra were acquired three times and averaged. The CDSSTR program [26] in Dichroweb (http://dichroweb.cryst.bbk.ac.uk) was used to estimate secondary structure content. The fit between experimental and reconstructed spectra was evaluated by their normalized root-mean-square deviation (NRMSD) (NRMSD $>0.05$ signifies a nonacceptable fit).

For thermal denaturation, $\mathrm{CARP}^{106-319}$ was assayed in the temperature range $25-80{ }^{\circ} \mathrm{C}$ and UN2A between $20{ }^{\circ} \mathrm{C}$ and $95{ }^{\circ} \mathrm{C}$. In both cases, the temperature increase rate was $1{ }^{\circ} \mathrm{C} \mathrm{min}^{-1}$ with an incubation time of $90 \mathrm{~s}$ at each integral degree. Each spectrum was collected twice and averaged. Thermal denaturation curves were calculated at $\lambda=208 \mathrm{~nm}$ for CARP ${ }^{106-319}$ (as this was the region of larger spectral change) and $\lambda=220 \mathrm{~nm}$ for UN2A, and the melting temperature $T_{\mathrm{m}}$ obtained from the first derivative.

\section{Size exclusion chromatography with multiangle laser light scattering}

The molecular mass (MM) of protein samples was determined by size exclusion chromatography with multiangle laser light scattering (SEC-MALLS) on an ÅKTA pure (GE healthcare, Little Chalfont, UK) connected to a MALLS detector and a differential refractive index (DRI) detector (DAWN HELEOS-II and Optilab TrEX; Wyatt Technology, Santa Barbara, CA, USA). The proteins were in a $25 \mathrm{~mm}$ HEPES pH7.5, $100 \mathrm{~mm} \mathrm{NaCl}$ solution that had been three times filtrated $(0.22 \mu \mathrm{M}$ filter $)$ and degassed. All measurements were on a HiLoad Superdex75 10/300 column (GE

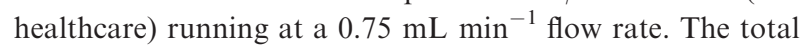
amount of protein injected was $\sim 1 \mathrm{mg}$ (at an approximate concentration of $2 \mathrm{mg} \mathrm{mL}^{-1}$ ). The system was calibrated using bovine serum albumin prior to the measurements.

\section{NMR spectroscopy}

2D TOCSY (mixing time $40 \mathrm{~ms}$ ) and NOESY (mixing time $100 \mathrm{~ms}$ ) spectra from unlabeled UN2A sample at $15 \mathrm{mg} \mathrm{mL}^{-1}$ were collected at $298 \mathrm{~K}$ in $25 \mathrm{~mm}$ HEPES pH7.5, $100 \mathrm{~mm} \mathrm{NaCl}, 3 \mathrm{~mm} \beta-\mathrm{ME}, 5 \%[\mathrm{v} / \mathrm{v}]{ }^{2} \mathrm{H}_{2} \mathrm{O}$ on an Avance III $600 \mathrm{MHz}$ spectrometer equipped with CryoProbe (Bruker, Karlsruhe, Germany). Spectra were processed with TopSpin (Bruker) and referenced to the external standard trimethylsilylpropanoic acid.

\section{Small-angle X-ray scattering}

Small-angle X-ray scattering (SAXS) data were collected at the B21 beamline of the Diamond Light Source synchrotron (Didcot, UK) using the integrated SEC-SAXS setup including the HPLC device Agilent 1260C (Santa Clara, CA, USA). Protein samples $(45 \mu \mathrm{L}$ volume) at a concentration of $13.3 \mathrm{mg} \mathrm{mL}^{-1} \mathrm{UN} 2 \mathrm{~A}, 13.4 \mathrm{mg} \mathrm{mL}^{-1}$ UN2A-Ig81， $14.9 \mathrm{mg} \mathrm{mL}^{-1}$ CARP : UN2A-Ig81 were injected onto a pre-equilibrated Shodex KW403 column (25 mm HEPES pH7.5, $100 \mathrm{~mm} \mathrm{NaCl)} \mathrm{and} \mathrm{SEC} \mathrm{performed}$ at a flow rate of $0.16 \mathrm{~mL} \mathrm{~min}{ }^{-1}$. Frames were collected for the entire eluate using an exposure time of $3 \mathrm{~s}$ per frame and a sample cell thermostated to $20{ }^{\circ} \mathrm{C}$. X-ray scattering was recorded on a Pilatus $2 \mathrm{M}$ detector (Dectris, BadenDaettwil, Switzerland) at a sample to detector distance of $3.9 \mathrm{~m}$ and a $\lambda=1 \AA$. Data processing used SCÅTter [27]. Scattering curves were analyzed with SCÅTTER and PRIMUS $[27,28]$ to determine the radius of gyration $\left(R_{\mathrm{g}}\right)$, the maximum dimension $\left(D_{\max }\right)$, the pair distribution function $P(r)$, and the experimental MM. Low-resolution ab initio models were calculated without the imposition of symmetry restraints using DAMMIF [29]. Twenty independent models were generated and averaged with DAMMAVER [30] and subjected to final refinement in DAMMIN [31].

\section{Crystal structure determination of domain Ig81}

Domain Ig81 was crystallized using a nanovolume dispenser robot (Innovadyne, Santa Rosa, CA, USA) on 96well Intelliplates using a sitting drop setting at $19^{\circ} \mathrm{C}$. Crystals grew from solutions containing $0.2 \mathrm{M} \mathrm{MgCl}_{2}$, $0.1 \mathrm{M}$ Tris $\mathrm{pH} 8.5,30 \%$ [w/v] PEG 4000. Ig81 was at a concentration of $38.5 \mathrm{mg} \mathrm{mL}^{-1}$. The precipitant : protein drop ratio was $200: 100 \mathrm{~nL}$. Crystals were vitrified in $\mathrm{LN}_{2}$ in cryo-protection medium $(20 \%[\mathrm{v} / \mathrm{v}]$ ethylene glycol, $20 \%[\mathrm{v} / \mathrm{v}]$ isopropanol, $0.2 \mathrm{M} \mathrm{MgCl}_{2}, 0.1 \mathrm{M}$ Tris pH8.5) and used in data collection. X-ray diffraction data were processed using XdS/XsCale [32] (Table 1). Phasing was by molecular replacement in PHASER [33] using Ig10 from titin (PDB 4QEG) as search model. The model of Ig81 was created with automatic model building in ARP/ WARP [34] and manual rebuilding in COOT [35]. Model refinement used PHENIX.REFINE [36].

\section{Results}

\section{The ankyrin repeat domain of CARP forms dimers with high helical content}

CARP binds titin $\mathrm{N} 2 \mathrm{~A}$ via its $\mathrm{C}$-terminal AR domain [8]. To study this interaction, we created an N-terminally truncated CARP construct corresponding to the titin-binding domain, CARP ${ }^{106-319}$. The overexpression of CARP $\mathrm{C}^{106-319}$ in E. coli yielded $7 \mathrm{mg}$ of purified sample per $1 \mathrm{~L}$ culture (Data S1). Analysis of CARP $^{106-319}$ by SEC-MALLS resulted in a measured MM of 48.6 kDa (Table 2; Data S2), indicating that CARP $^{106-319}$ forms dimers (MM calculated from 
Table 1. X-ray data processing statistics and model refinement parameters. EDO, ethylene glycol; IPA, isopropanol.

\begin{tabular}{|c|c|}
\hline & $\lg 81$ \\
\hline PDB code & 5JOE \\
\hline Space group & $P 6_{5} 22$ \\
\hline \multicolumn{2}{|l|}{ Cell dimensions } \\
\hline$a, b, c(\AA)$ & $115.31,115.31,52.23$ \\
\hline$\alpha, \beta, \gamma\left({ }^{\circ}\right)$ & $90,90,120$ \\
\hline Solvent content (\%) & 43 \\
\hline Matthews coefficient $\left(\AA^{3} / \mathrm{Da}\right)$ & 2.4 \\
\hline Copies in asymmetric unit & 1 \\
\hline \multicolumn{2}{|l|}{ X-ray data } \\
\hline X-ray source & DIAMOND I04-1 \\
\hline Detector & PILATUS 6M-F \\
\hline Wavelength $(\AA)$ & 0.9282 \\
\hline Resolution $(\AA)$ & $28.83-2.0(2.05-2.0)$ \\
\hline Unique reflections & 14310 (993) \\
\hline Multiplicity & $11.47(11.67)$ \\
\hline Completeness, \% & $99.8(98.6)$ \\
\hline$<\mid / \sigma(I)>$ & $23.28(2.87)$ \\
\hline$R_{\text {sym }}(\mathrm{I})$ & 10.4 (87.9) \\
\hline $\mathrm{CC}(1 / 2)$ & $99.9(86.5)$ \\
\hline \multicolumn{2}{|l|}{ Refinement } \\
\hline No. of reflections & $14290 / 430$ \\
\hline \multicolumn{2}{|l|}{ Working/test set } \\
\hline Protein atoms/waters & $765 / 179$ \\
\hline Ligands & EDO $\times 2, I P A \times 1$ \\
\hline$R_{\text {factor }} / R_{\text {free }} \%$ & $0.1775 / 0.2184$ \\
\hline RMSD bond length, $\AA$ & 0.003 \\
\hline RMSD bond angle, ${ }^{\circ}$ & 0.71 \\
\hline
\end{tabular}

sequence is $24.1 \mathrm{kDa}$ ). This result was unexpected as CARP ${ }^{106-319}$ lacks the N-terminal coiled-coil motif thought to be indispensible for CARP dimerization [8]. Our findings reveal now that the AR domain can contribute to the $\mathrm{N}$ terminus-led dimerization of CARP.

Next, we estimated the secondary structure content of CARP ${ }^{106-319}$ using CD spectra. These calculations indicated that CARP ${ }^{106-319}$ contains approximately $41 \%$ helical and $13 \% \quad \beta$-turn elements (NRMSD = 0.03; Fig. 2C). The result is in excellent agreement with secondary structure predictions performed using PSIPRED (http://bioinf.cs.ucl.ac.uk/psipred/; [37]), Jpred4 (http://www.compbio.dundee.ac.uk/jpred; [38]), and PCI-SS (http://bioinf.sce.carleton.ca/PCISS/start. php; [39]). Predictions consistently suggested the

Table 2. Molecular mass analysis of CARP and N2A samples.

\begin{tabular}{llll}
\hline Sample & $\begin{array}{l}\text { Sequence } \\
\text { (MM; kDa) }\end{array}$ & $\begin{array}{l}\text { SEC-MALLS } \\
\text { (MM; kDa) }\end{array}$ & $\begin{array}{l}\text { Oligomeric } \\
\text { state }\end{array}$ \\
\hline CARP $^{106-319}$ & 24.1 & 48.6 & Dimer \\
N2A & 33.9 & 36.0 & Monomer \\
UN2A & 13.3 & 13.1 & Monomer \\
CARP $^{106-319}:$ N2A & 58.0 & 59.4 & $1: 1$ \\
\hline
\end{tabular}

presence of 12 short helices indicative of the existence of six AR motifs, amounting to $\sim 40 \%$ helical content. AR motifs contain $\sim 33$ residues that fold into two short $\alpha$-helices linked by a tight turn, forming a helixloop-helix $\alpha$-hairpin structure where each adjacent $\alpha$ helix is arranged in an antiparallel fashion [40]. AR units pack consecutively into an array, being linked by a loop of variable length that projects outward from the helices at a $90^{\circ}$ angle. Upon stacking of the repeats, the fold adopts a slightly concave shape. Although there is no strict sequence conservation in AR motifs, their composition approximates the consensus 'G-TPLHhA---G-h[-]hh-h--GA-h-A[+]', where $h$ indicates a hydrophobic residue and $[-]$ and $[+]$ negatively and positively charged residues, respectively [41]. Prominent features are the conserved TPLH sequence in the first $\alpha$-helix that is involved in a tight network of hydrogen bonds of structural importance and the LL-GA motif at the end of each individual AR. The TPLH feature is clearly recognizable in each of the six predicted AR in CARP $\mathrm{P}^{106-319}$ (Fig. 2A). Thus, taking $\mathrm{CD}$ data and identifiable sequence motifs together, we concluded that the C-terminal domain of CARP contains six AR motifs. In agreement, a representative 3D-model of CARP ${ }^{106-319}$ calculated independently with I-TASSER [42] contained six AR motifs (Fig. 2B).

The stability of the CARP ${ }^{106-319}$ fold was then estimated by thermal denaturation. For this, changes in the $\mathrm{CD}$ spectrum upon temperature increase were used to calculate the melting temperature $\left(T_{\mathrm{m}}\right)$ of the domain. This yielded a $T_{\mathrm{m}}$ value of $43{ }^{\circ} \mathrm{C}$ (Fig. 2D). The result was confirmed using differential scanning fluorimetry (DSF), which exactly reproduced the value (Data S3).

\section{The unique titin N2A domain has a helical and thermally stable fold}

In titin, the unique sequence $\mathrm{UN} 2 \mathrm{~A}$ has been reported as the CARP-binding site [8]. UN2A is believed to be intrinsically disordered (e.g., [8]). In support of this view, the disorder predictor PONDR-fit [43] suggested notable portions of disorder in the $\mathrm{N}$ - and $\mathrm{C}$-terminal fractions of UN2A, with only a small central region proposed as structured. In contrast, disorder predictors DISEMBL [44], GLOBPLOT2 [45], and PREDICT PROTEIN [46] did not consistently identify any areas of significant disorder. The latter agrees with secondary structure predictions from PSIPRED [37], Jpred4 [38], and PCISS [39] that estimate that UN2A has an $\alpha$-helix rich secondary structure (approximately 60-70\% helical content; Fig. 3A). 
A

Sequence: VVKEPEPE I I T E P VDVF TFLKAALENKLPVVEKFLSDKNN P DVCDEYKRTALHRACLEGH Confidence: 999999764589991099999999959999999999969910109889999998999998199 Prediction: TT T T TT T T T T T T T T T TTHнHнHнHнT THHнHнHнHнTTT T T T TTTTT T TTHннннннTTT

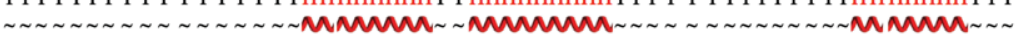

Sequence: LA I VEKLME A GA $\mathrm{Q}$ I E FRDMLES TA I HWA SRGGLDVLKL L L NKGAK I S ARDK LL STALHY Confidence: 999999999610910998999999989999996999999991098999999999999999999

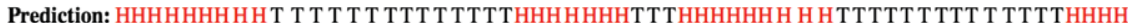

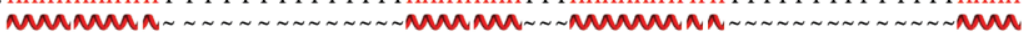

Sequence: AVR TGHY ECA EHL I A CEAPLNAKDRE GD TPLHDAVRLNR Y KM I RLL I MYGAD LNI KNCAG Confidence: 9986999999999997999999899999989999988999999999996991099889999 Prediction: HHH T TTH H HH H H H H H TT T T TTTTTT T TTHHHHHHHTTT H H HHHHHHHTTT T TTTTTTTT

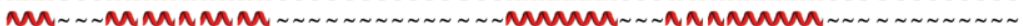

Sequence: KTPMDLVLHWQNGTKAI FDSLRENSYKTSR I ATF

Confidence: 99999991093999999999999989991326999 Prediction: TTHHHHHHHT T T T THHHHHHHHHTTT T TTTTTTT

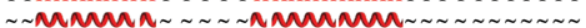

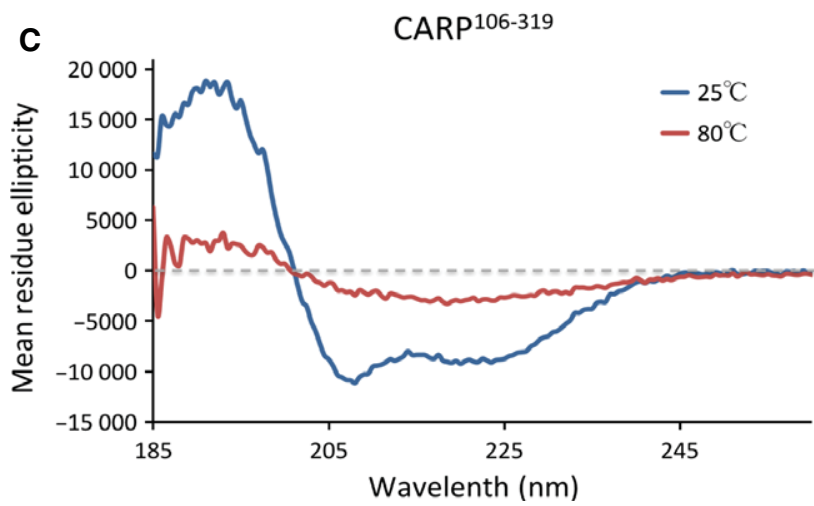

B

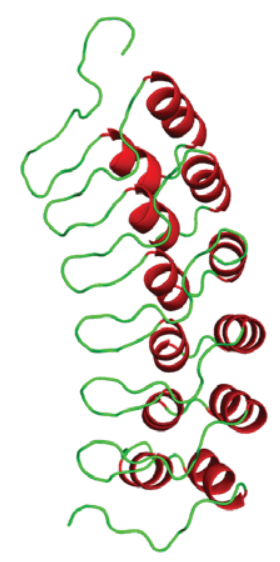

Fig. 2. The fold of the C-terminal AR domain from CARP. (A) Secondary structure prediction from sequence data for CARP ${ }^{106-319}$ by the PCI-SS server [39]. Sequence signatures typical of the ankyrin repeat motif are boxed; (B) Predicted 3D-model of the CARP ${ }^{106-319}$ fold calculated using I-TASSER (estimated TM-score $=0.87 \pm 0.07$; confidence score $C$-score $=1.13$ ) [42]; (C) CD spectra of CARP ${ }^{106-319}$ recorded in $20 \mathrm{~mm}$ sodium phosphate buffer pH7.5 at $25{ }^{\circ} \mathrm{C}$ (blue), exhibiting features typical of an $\alpha$-helical protein, and at $80{ }^{\circ} \mathrm{C}$ (red) upon being thermally denatured; (D) Thermal denaturation curve of CARP ${ }^{106-319}$ derived from the change in its CD spectrum at $\lambda=208 \mathrm{~nm}$.

To test these predictions, we produced UN2A recombinantly in E. coli (yield: $\sim 30 \mathrm{mg}$ per $1 \mathrm{~L}$ culture; Data S1). SEC-MALLS analysis measured UN2A MM as $13.3 \mathrm{kDa}$. This value is in excellent agreement with its theoretical MM (13.1 kDa), confirming that UN2A is monomeric (Table 2; Data S2). Next, we estimated the secondary structure content of UN2A using CD. Spectra confirmed that this is a highly helical protein (calculated helical content of $\sim 62 \%$; NRMSD $=0.01$; Fig. $3 \mathrm{C}$ ). Supporting this result, we found similarity between a central UN2A portion (accounting for approximately one-third of its sequence) and a fragment of the unique cardiac myosin binding protein- $\mathrm{C}$ motif ( $40 \%$ identity; $71 \%$ similarity) that forms a three-helix bundle [47] (Fig. 3B).

Furthermore, we carried out a preliminary study of UN2A using ${ }^{1} \mathrm{H}-{ }^{1} \mathrm{H}$ NOESY and TOCSY NMR experiments. The large number of sequential $\mathrm{H}^{\mathrm{N}} / \mathrm{H}^{\mathrm{N}}$ (Fig. 3D) and strong intraresidue $\mathrm{H}^{\mathrm{N}} / \mathrm{H} \alpha$ (Data S4) cross-peaks observed in the 2D-NOESY spectrum confirmed that this is a highly helical protein. Additionally, a large number of NOE cross-peaks were observed between aromatic and aliphatic residues (6.67.2 p.p.m. region; Data S4), suggesting that at least some of the aromatic residues contact simultaneously several aliphatic residues, which normally occurs in a hydrophobic cluster. These NMR characteristics are consistent with a mutual packing of helices stabilized by hydrophobic interactions. No sharp backbone $\mathrm{H}^{\mathrm{N}}$ signals were observed in the 2D TOCSY spectrum that would indicate flexible, unstructured regions in the domain (Data S4). This led us to conclude that UN2A helices are arranged in a 3D-fold rather than being a dynamic chain of loose, transiently forming helices. However, overall, NMR signals were significantly broader than expected for a globular protein of this size. A likely explanation is an elongated shape of the $\mathrm{UN} 2 \mathrm{~A}$ molecule that reduces rotational correlation 
A

Sequence: DERKKQEK I EGDLRAMLKKT P I LKKGAGEEE I I I MELLKNVDPKEYEKYARMYG I TDFR

Confidence: 999999988853899885386436789999996789998389976999999982889999

Prediction: TTTTTT TTTTTTHHHHHHTT TT TTT TTTTTTT TTHHHHHT T TTHHHHHHHHHHHTHHHHH

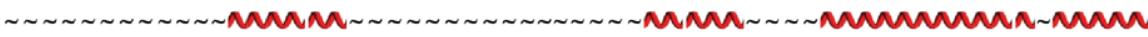

Sequence: GLLQAFELLKQSQEE E THRLE I EE I ER SERDEKE F E ELVS F I QQRL SQTE

Confidence: 99999998368878899999999997167778999999999999836999

Prediction: HHHHHHHHHTTTHHHHHHHHHHHHHHHTTTTHHHHHHHHHHHHHHHTTTT

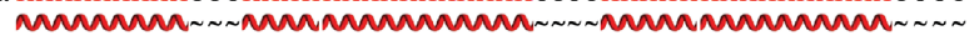

B

UN2A: EIDIMELLKNVDPKEYEKYARMYGITDFRGLLQAFELLKQSQ

$\mathrm{E} \mathrm{D}+\mathrm{E}+\mathrm{L}+\quad \mathrm{P}$ EYE $+\mathrm{A}+\mathrm{G}+\mathrm{TD} \mathrm{RG}+\mathrm{L}+++\mathrm{KQ}+$

MyBPC3 : EEDVWEILRQAPPSEYERIAFQHGVTDLRGMLKRLKGMKQDE

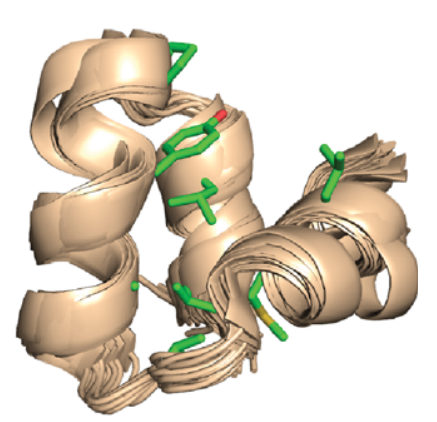

C
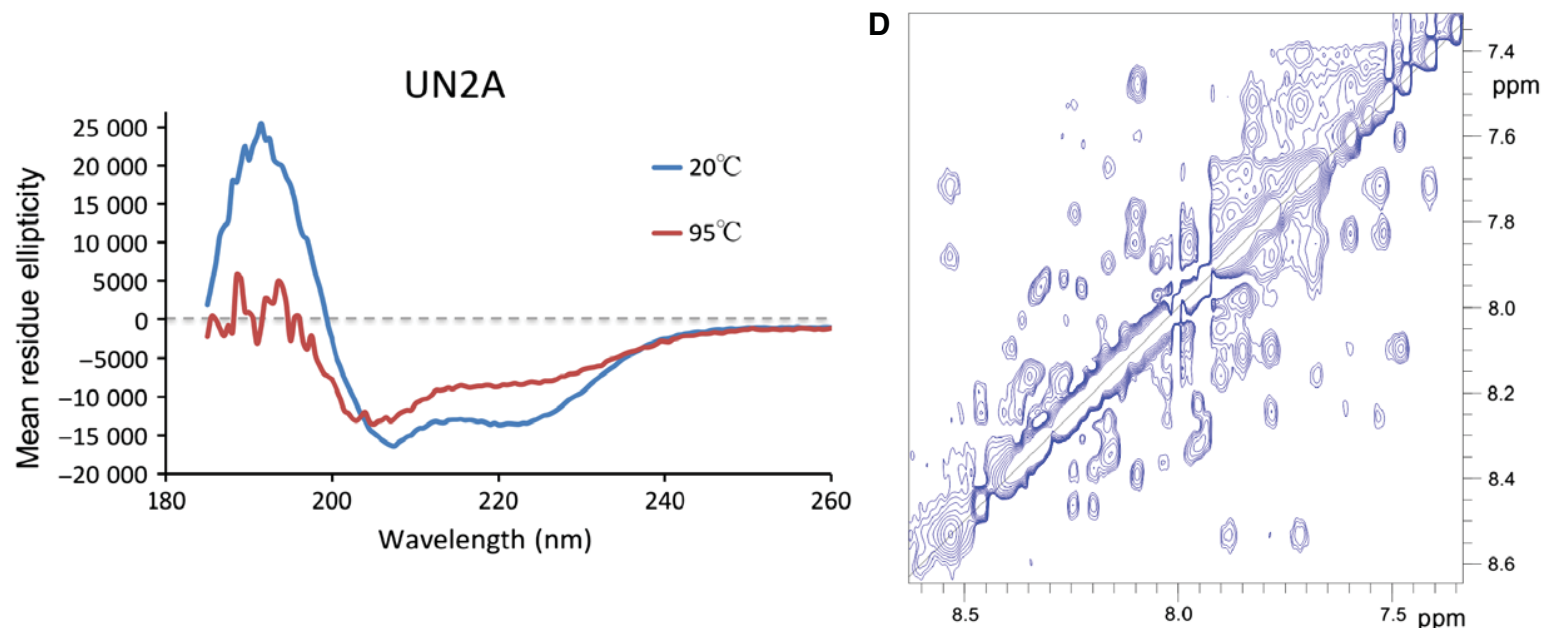

Fig. 3. Analysis of the UN2A fold. (A) Secondary structure prediction of UN2A from sequence data using the PCI-SS server [39]. Boxed (blue) is a sequence segment in the central portion of UN2A with shared similarity to a helical motif from MyBP-C3; (B) Sequence alignment of the segment common to MyBP-C3 and UN2A where conserved groups are indicated. The NMR structure of the MyBP-C3 fragment (PDB 2LHU) is shown and the hydrophobic residues conserved in UN2A explicitly displayed. The conservation of these groups suggest a similar helical packing of this segment of UN2A; (C) CD spectra of UN2A recorded in $20 \mathrm{~mm}$ sodium phosphate buffer pH7.5 at $25{ }^{\circ} \mathrm{C}$ (Ellipticity); (D) $\mathrm{H}^{\mathrm{N}} / \mathrm{H}^{\mathrm{N}}$ region of $2 \mathrm{D}$ NOESY spectrum showing a large number of contacts between backbone $\mathrm{H}^{\mathrm{N}}$ protons characteristic of helical secondary structure.

time. This deduction is strongly supported by the elution profile of UN2A in SEC, where UN2A elutes at much lower exclusion volume than expected for a protein of this MM (Data S5), indicative of a highly anisometric molecular shape. Taken together, NMR and SEC data suggested at this stage that UN2A is likely to adopt an elongated helical fold.

Finally, we estimated the stability of the UN2A fold by $\mathrm{CD}$-monitored thermal denaturation. Unexpectedly, the temperature increase only yielded a small, noncooperative change in $\mathrm{CD}$ signal, which did not allow calculating a $T_{\mathrm{m}}$ value for UN2A (Fig. 3C). We then incubated UN2A samples at $95{ }^{\circ} \mathrm{C}$ for $90 \mathrm{~s}$ and at $99{ }^{\circ} \mathrm{C}$ for $10 \mathrm{~min}$. In both cases, UN2A retained high levels of secondary structure (Data S6). This suggested that UN2A has a stable fold and that its helices are not merely transient formations.

\section{CARP forms a robust complex with the dual domain UN2A-Ig81 segment of titin}

To validate UN2A as the CARP-binding locus of titin $\mathrm{N} 2 \mathrm{~A}$, we tested the binding of the recombinant CARP ${ }^{106-319}$ and UN2A samples using SEC. However, only a modest cosegregation of the samples could be observed (Fig. 4B), indicating that the complex forms only weakly. We then extended the UN2A construct to include its flanking domains: constructs Ig80-UN2A 

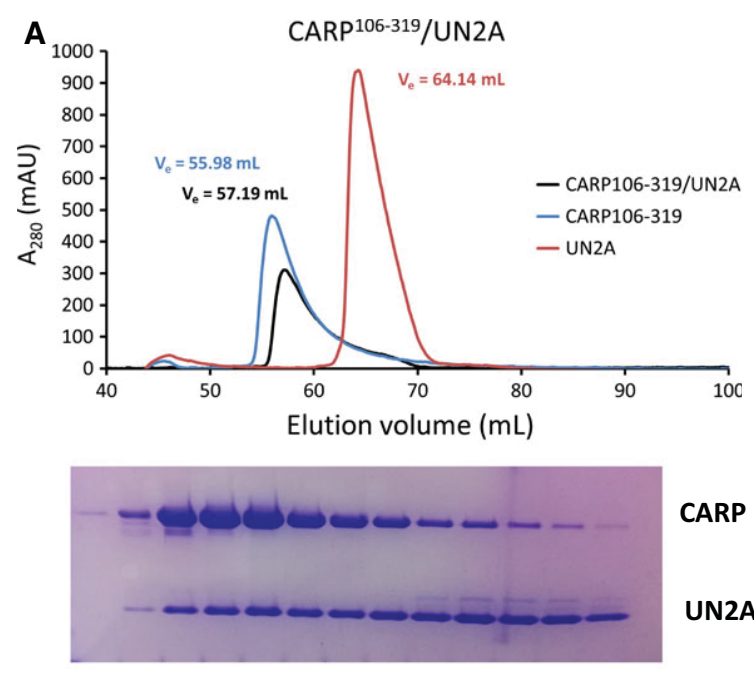

CARP

UN2A

$\begin{array}{lllllllllllll}55 & 56 & 58 & 59 & 60 & 61 & 63 & 65 & 66 & 67 & 68 & 69 & 70\end{array}$

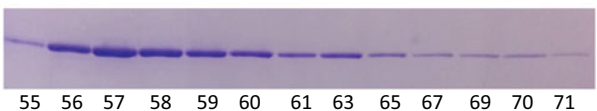

CARP

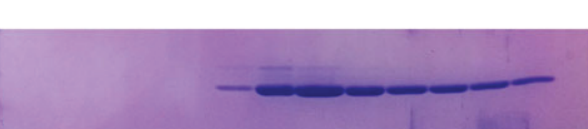

$\begin{array}{lllllllllllll}55 & 56 & 58 & 60 & 61 & 63 & 64 & 65 & 66 & 67 & 68 & 69 & 70\end{array}$
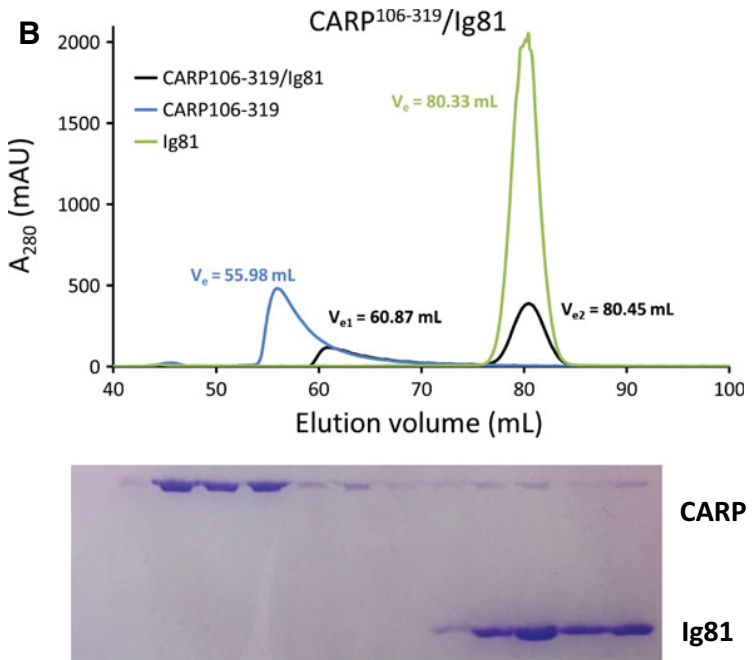

CARP

Ig81

$\begin{array}{lllllllllllll}56 & 60 & 61 & 62 & 64 & 67 & 71 & 75 & 78 & 79 & 80 & 81 & 83\end{array}$

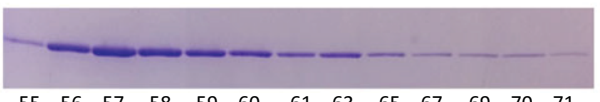

CARP

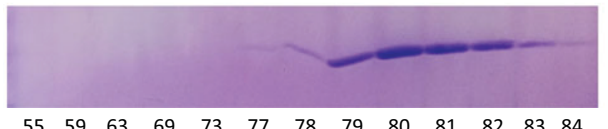

$\lg 81$
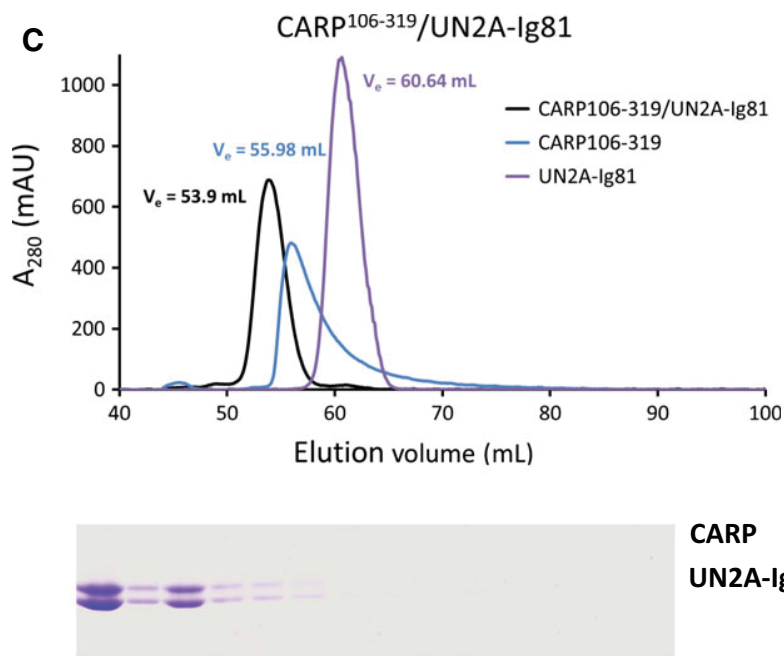

CARP

UN2A-Ig81

$\begin{array}{lllllllllllll}53 & 54 & 55 & 56 & 57 & 58 & 59 & 60 & 61 & 63 & 65 & 67 & 69\end{array}$

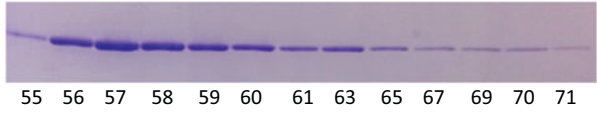

CARP

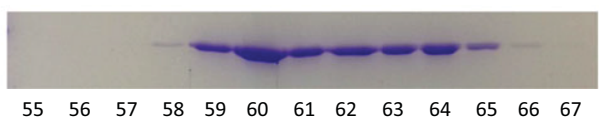

Fig. 4. Analysis of the complexation of CARP and N2A species. Complexes of CARP ${ }^{106-319}$ and (A) UN2A, (B) Ig81, and (C) UN2A-Ig81 mixed at 1 : 1 molar ratio studied by SEC using a same Superdex75 16/60 column (GE Healthcare) in 25 mM HEPES pH7.5, 100 mM NaCl. Only UN2A-Ig81 yields a strong cosegregation with CARP ${ }^{106-319}$. 
and UN2A-Ig81 were generated. Ig80-UN2A could not be produced solubly in E. coli, but UN2A-Ig81 was obtained in a yield of $10 \mathrm{mg}$ per $1 \mathrm{~L}$ culture (Data $\mathrm{S} 1)$. SEC showed that the interaction between UN2AIg81 and CARP ${ }^{106-319}$ is robust, with a clear cosegregation of species permitting the isolation of the complex (Fig. 4A). Hence, we deduced that Ig81 must be part of the CARP-binding site in titin. However, when we tested the complexation of CARP ${ }^{106-319}$ with the isolated Ig81, no cosegregation was observed suggesting that Ig81 on its own does not interact detectably (Fig. 4C). We thus concluded that Ig81 and UN2A cooperate in forming a shared binding site for CARP.

\section{Binding to titin disrupts the dimeric state of the ankyrin repeat domain of CARP}

As CARP ${ }^{106-319}$ forms dimers but N2A components are monomeric (Table 2), we studied the stoichiometry of the complex using SEC-MALLS. To better resolve complexed and single species, we used an extended segment of titin N2A comprising Ig80-UN2A-Ig81, here termed N2A (Fig. 1). N2A was produced recombinantly with a yield of $8 \mathrm{mg}$ of pure protein per $1 \mathrm{~L}$ culture (Data S1). The analysis of the CARP ${ }^{106-319}:$ N2A complex by SEC-MALLS yielded a MM of $59.4 \mathrm{kDa}$ (Table 2; Data S2). As the theoretical MM of CARP ${ }^{106-319}$ is $24.1 \mathrm{kDa}$ and that of $\mathrm{N} 2 \mathrm{~A}$ is $33.9 \mathrm{kDa}$, the measured $\mathrm{MM}$ is in excellent agreement with a $1: 1 \mathrm{CARP}^{106-319}$ : N2A complex. This implies that the CARP ${ }^{106-319}$ dimer interface must be disrupted by its binding to titin N2A, so that N2A binding is in competition with ARmediated CARP dimerization.

\section{Biophysical characterization of the CARP : titin complex and its components}

We studied the overall molecular features of UN2A, UN2A-Ig81, and the CARP : UN2A-Ig81 complex using SAXS (Fig. 5; Table 3). MM estimates indicated that all samples are predominantly monomeric in solution, agreeing with SEC-MALLS data. The experimental $R_{\mathrm{g}}$ and $D_{\max }$ values pointed to elongated molecular shapes for all constructs, but specially UN2A and UN2A-Ig81. Specifically, the $R_{\mathrm{g}}$ and $D_{\max }$ values of UN2A (21.7 $\AA$ and $9.0 \mathrm{~nm}$, respectively) were roughly twice those of a globular protein of same mass (13.5 and $3.5 \mathrm{~nm}$, respectively, for a hydrated spherical protein particle of density $\left.1.35 \mathrm{~g} \mathrm{~cm}^{-3} ; \mathrm{Rg}^{2}=3 / 5 . r^{2}\right)$. The elongated shape of these samples was also confirmed by the overall appearance of the pair distance distribution function $P(r)$ that defines the frequency of distances $r$ joining two volume elements in the molecule.
The $P(r)$ functions of UN2A and UN2A-Ig81 displayed a skewed appearance characteristic of elongated structures, and exhibited a tail indicative of an extended protrusion (Fig. 5). The marked tail of the $P(r)$ function further points to a modest internal dynamics in these samples, as marked motions would result in a disappearance or smearing of this feature.

The interpretation of SAXS data in terms of lowresolution molecular shapes resulted in elongated structures for UN2A and UN2A-Ig81 (Fig. 5), consistent with deductions above. The ab initio model of the CARP : UN2A-Ig81 complex suggested the binding of CARP in transversal orientation at the junction of the UN2A and Ig81 domains (Fig. 5), in agreement with expectations.

\section{The crystal structure of Ig81 reveals individualized fold features}

The numerous Ig domains along the titin chain (>300) share high levels of structural and sequence similarity. Yet, certain Igs have achieved structural and functional differentiation, acting as specific loci for the recruitment of sarcomeric proteins to titin. To reveal whether Ig81 presents individualized features that could support its specific role in CARP binding, we elucidated its atomic structure using X-ray crystallography (Table 1).

The structure of Ig81 reveals a classical Ig-I fold, characteristic of domains from titin. However, Ig81 has a divergent $\mathrm{BC}$-loop at the $\mathrm{N}$-terminal pole of its fold that does not conform with the canonical features of either of the Ig subtypes of titin: the ' $\mathrm{N}$-conserved' and ' $\mathrm{N}$-variable' types [48]. The ' $\mathrm{N}$-conserved' type is characterized by the presence of a long FG $\beta$-hairpin hosting a NxxG motif, the prevalence of a PP motif within the $\mathrm{N}$-terminal $\beta$-strand $\mathrm{A}$, and a modestly long $\mathrm{BC}$-loop rich in proline residues. The correlated conservation of these three attributes derives from their tight mutual packing at the N-terminal pole of the fold [48]. By contrast, the 'N-variable' Ig subtype is defined by shortened BC and FG loops that do not pack against each other [48]. The loop structure is highly conserved within each Ig subtype (Data S7), with the divergence resulting from identifiable sequence differences that alter both the length and composition of these loops in each subtype. Ig81 shows features typical of the 'N-variable' subtype (presenting a short FG $\beta$-hairpin) but it displays an unusually long BC-loopthese unique characteristics do not conform to either subtype (Fig. 6; Data S7). The protruding BC-loop in Ig81 is accessible, being a good candidate for the mediation of interactions. Thus, it is conceivable that 

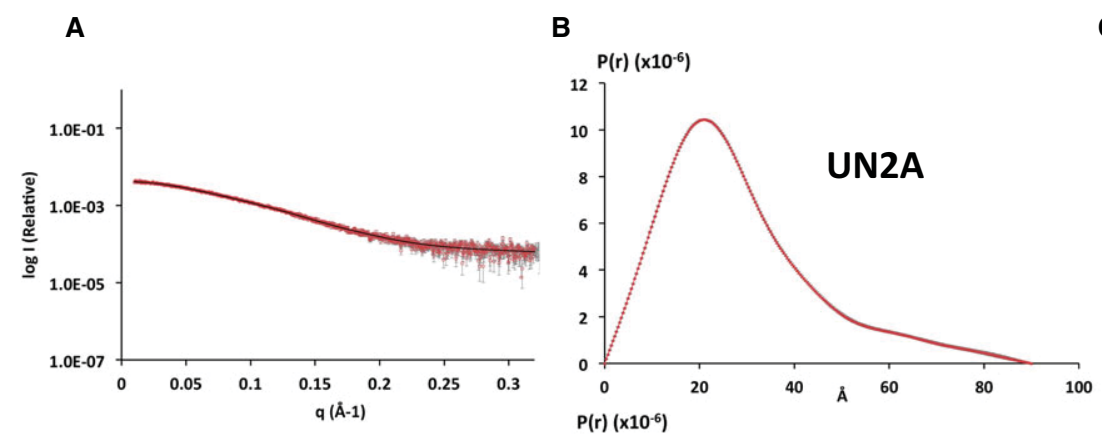

C
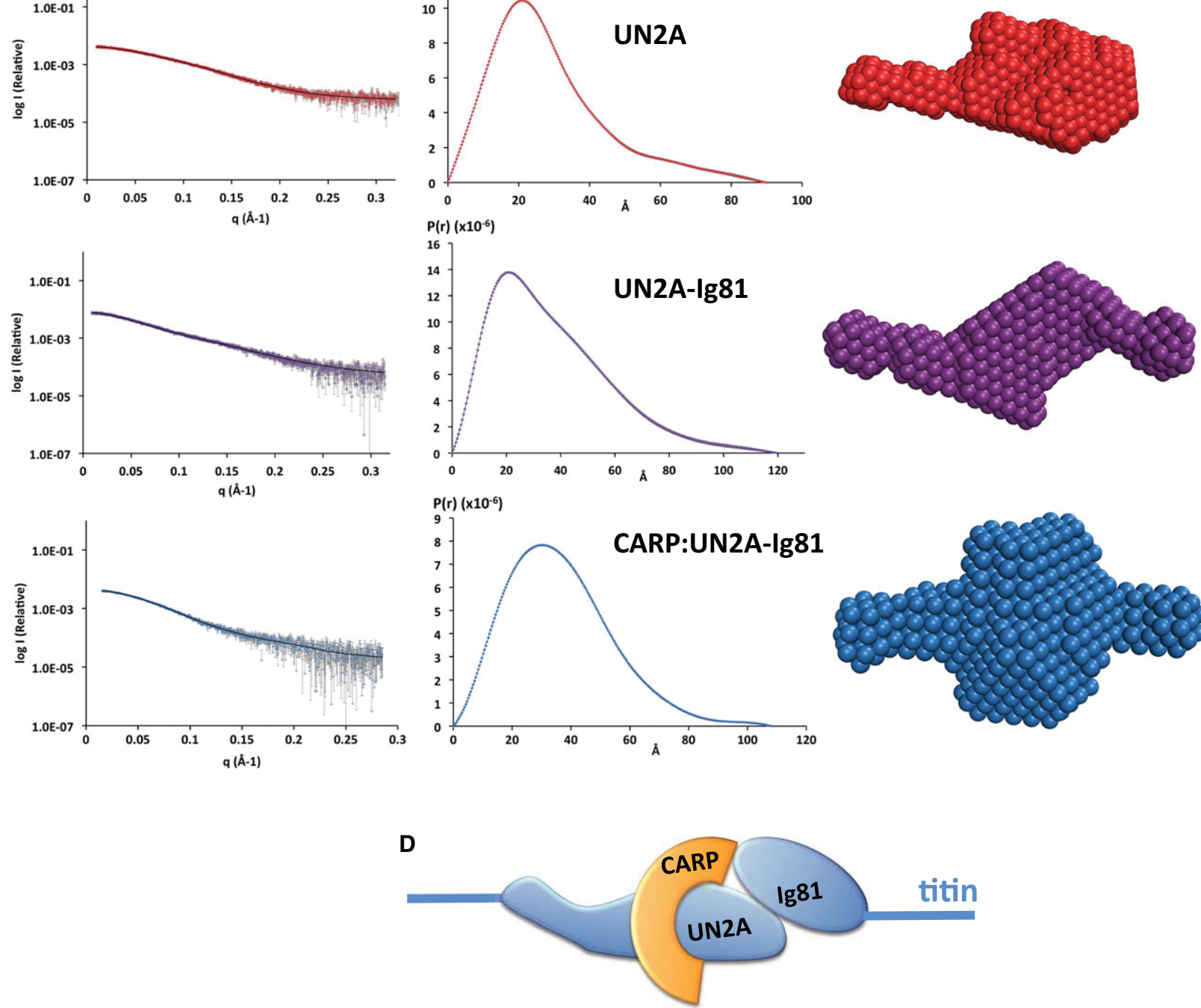

Fig. 5. SAXS data and ab initio models of the CARP/titin complex and its components. (A) Experimental scattering is displayed as dots with error bars, while the curves computed from the ab initio models are given as continuous lines; (B) Distance distribution functions; (C) $a b$ initio sphere models. Bringing confidence to the calculations, it can be observed that shapes of larger constructs reproduce and expand the features of the smaller segments. Comparison of UN2A and UN2A-Ig81 envelopes suggest that UN2A has an N-terminal protrusion that contributes to its acutely elongated shape. The extension on the right side of UN2A-lg81 fits an Ig domain within. The envelope of the CARP : UN2A-Ig81 complex shows a transversal enlargement, whose dimensions agree with those of the I-TASSER model of CARP106-319 that fits within; (D) Schematical interpretation of the CARP : UN2A-Ig81 complex.

this loop, which is located at the UN2A-Ig81 interface, might play a role in the recruitment of CARP to this locus of titin.

Finally, we explored whether the elongated BCloop in $\operatorname{Ig} 81$ affected the stability of its fold. We derived the $T_{\mathrm{m}}$ of $\mathrm{Ig} 81$ by thermal unfolding monitored by DSF, which yielded a value of $67^{\circ} \mathrm{C}$ (Data S3). This value indicated that $\mathrm{Ig} 81$ has a robust fold. The high $T_{\mathrm{m}}$ of Ig81 correlates with the thermostability of UN2A, and together with SAXS data, suggest that the UN2A-Ig81 doublet is a structurally stable locus of titin.

\section{Discussion}

$\mathrm{N} 2 \mathrm{~A}$ is a small linker located at the junction of the two main springs of titin: the poly-Ig tandems that extend at low force and the PEVK-rich region that extends at high force [1 and references within]. The current view is that $\mathrm{N} 2 \mathrm{~A}$ is a largely unstructured region that extends upon 
Table 3. Molecular parameters calculated from scattering data.

\begin{tabular}{llllcl}
\hline & $\begin{array}{l}\mathrm{MM}_{\text {calc }} \\
(\mathrm{kDa})\end{array}$ & $\begin{array}{l}\mathrm{MM}_{\text {exp }} \\
(\mathrm{kDa})\end{array}$ & $R_{\mathrm{g}}(\AA)$ & $D_{\max }(\AA)$ & $\chi^{2}$ \\
\hline UN2A & 13.3 & 13.0 & $21.71 \pm 0.11$ & 90 & 1.38 \\
UN2A-Ig81 & 23.6 & 19.0 & $27.06 \pm 0.19$ & 120 & 1.28 \\
Complex & 47.7 & 37.5 & $27.87 \pm 0.22$ & $108-112^{\mathrm{a}}$ & 1.14 \\
\hline
\end{tabular}

MM, $R_{\mathrm{g}}, D_{\max }$ denote the molecular mass, radius of gyration, and maximal particle size, respectively. $\mathrm{MM}_{\mathrm{calc}}$ is the theoretical $\mathrm{MM}$ of the samples calculated from sequence data. $\chi 2$ is the discrepancy between the experimental curve and those computed from $a b$ initio sphere models.

In the CARP : UN2A-Ig81 complex, the protrusions are proportionally smaller than the bulkier core fold so their contribution to the $P(r)$ function in the form of a tail is also relatively smaller. We tested the veracity of the tail in the $P(r)$ function by exhaustively evaluating global fits and ab initio models for $D_{\max }$ values in the range 100-112 $\AA$. Larger $D_{\text {max }}$ values (108-112 $\AA$ ) yielded best results and ab initio models with more interpretable features. stretch, generating passive force. Unexpectedly, our data indicate that UN2A has an $\alpha$-helical 3D-fold of anisometric characteristics, which forms a structured complex with CARP. It is known that secondary structure elements determine the mechanical unfolding regime of proteins $[49,50]$. In helices, the main chain hydrogen bonds align with the helical axis that, in turn, commonly aligns with the force vector during pulling. As a result, helices undergo longitudinal shearing, so that their unfolding requires a force equivalent to the force needed to rupture one bond multiplied by the number of bonds in the helix. Thereby, helical motifs behave as constant force springs, displaying a force plateau while unfolding. This is contrary to entropic springs in which the force rises with extension (following Hooke's law) [51-53]. Thus, helices work in a truly elastic regime, undergoing rapid force-induced folding-refolding transitions, where little energy is dissipated so
A

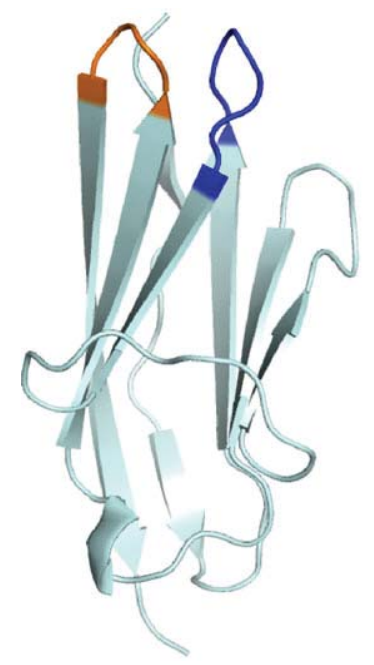

I1

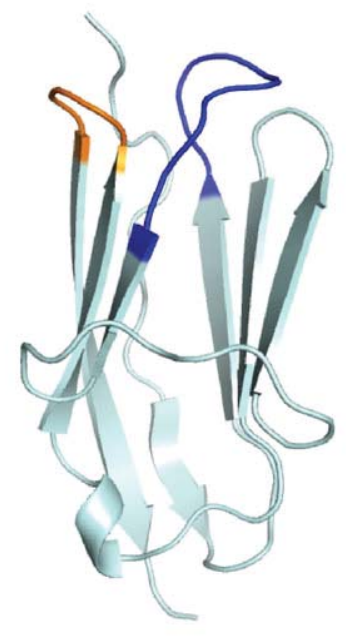

194

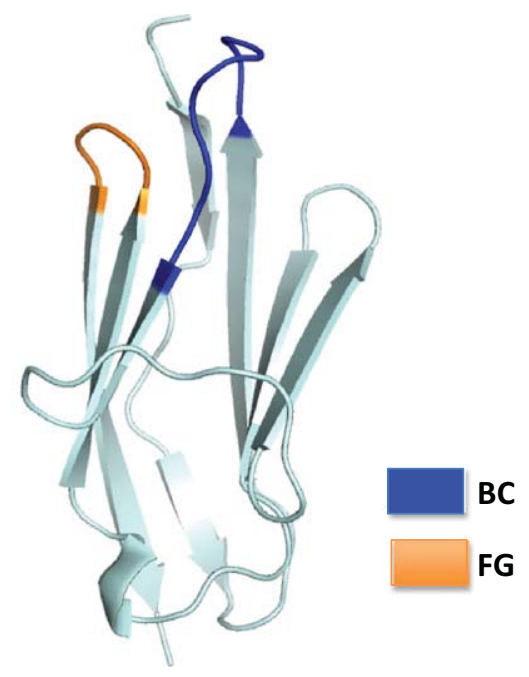

181

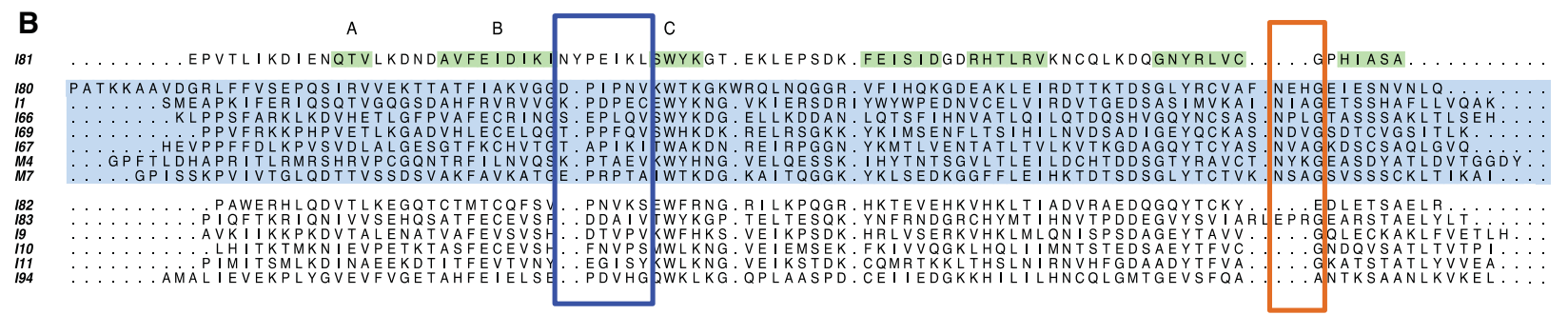

Fig. 6. Crystal structure of Ig81. (A) Cartoon structures of representative Ig subtypes in titin: I1 belongs to 'N-conserved' subtype and I94 to the 'N-variable' [48]. The subtypes have a different loop structure at their N-terminal pole. 181 has mixed features, with the extended conformation of its longer BC-loop given by its packing against the N-terminal $\beta$-strand $A$; (B) Sequence alignment of a selected set of Ig from titin. The ' $\mathrm{N}$-conserved' group is highlighted in blue. The $\beta$-strand composition of Ig81 is indicated in green. (The BC-loop and FG $\beta$ hairpin are indicated in A and B). Interestingly, Ig83 in the titin N2A region, which is truncated in mdm mice [9], has an unusual feature somewhat comparable to that of Ig81; namely, an extended FG $\beta$-hairpin. 
that the complete mechanical energy absorbed in the stretching cycle is released during relaxation. We speculate that the UN2A segment might act as a constant force spring that serves as a mechanical buffer in the sarcomeric I-band.

The stretch response of titin N2A is regulated by CARP binding. Yet, CARP shuttles from its sarcomeric localization in the I-band to the nucleus upon mechanical stress [7]. The response to stretch of CARP together with its ability to act as nuclear transcriptional regulator $[12,13]$ point to a role as possible translator of mechanical signals into gene expression processes in muscle [7]. Our data suggest that CARP mechanosensing could result from the dual domain nature of the UN2A-Ig81binding site. In such shared binding sites, an alteration of the twist or hinge angles between domains by stretch could sterically alter the affinity of the titin chain for the binding protein, thereby making the interaction mechanically sensitive [54]. In this respect, CARP : UN2A-Ig81 is reminiscent of another mechanosensory complex of titin, that of the E3 ubiquitin ligase MuRF1 with the tandem A168-A169-A170-TK in the sarcomeric M-line [55-57]. Like CARP : UN2A-Ig81, MuRF1 requires at least two titin domains for binding: A168A169 [55], with no single domain able to bind MuRF1 in isolation [57]. As in Ig81, Ig domain A169 has individualized features: a unique loop between $\beta$-strands A and $\mathrm{A}^{\prime}$. The mutagenesis of this loop abolished MuRF1 binding [56]. These shared features indicate that titin might use a general molecular strategy in the formation of sensory complexes. As a whole, findings from this work call now for an assessment of the mechanical resilience of UN2A and the impact on sarcomere performance of its binding to CARP.

\section{Acknowledgements}

We specially thank Michael Lockhart for his contribution to SAXS data collection. We thank DIAMOND for SAXS and PX radiation time. We acknowledge the financial support of the British Heart Foundation (PG/13/21/3007), the Leducq Foundation (TNE13CVD04) and the European Commission Marie Skłodowska-Curie Individual Fellowship (Titin Signals, 656636).

\section{Author contributions}

OM, JRF, and JB conceived and supervised the study; TZ, JRF, BF, JB, IB, and DJR designed and performed experiments and analyzed data; SL provided materials and scientific support; OM, TZ, and JB wrote the manuscript; all authors made manuscript revisions.

\section{References}

1 Linke WA and Hamdani N (2014) Gigantic business: titin properties and function through thick and thin. Circ Res 114, 1052-1068.

2 Gerull B (2015) The rapidly evolving role of titin in cardiac physiology and cardiomyopathy. Can J Cardiol 31, 1351-1359.

3 Freiburg A, Trombitas K, Hell W, Cazorla O, Fougerousse F, Centner T, Kolmerer B, Witt C, Beckmann JS, Gregorio CC et al. (2000) Series of exonskipping events in the elastic spring region of titin as the structural basis for myofibrillar elastic diversity. Circ Res 86, 1114-1121.

4 Cazorla O, Freiburg A, Helmes M, Centner T, McNabb M, Wu Y, Trombitás K, Labeit $\mathrm{S}$ and Granzier H (2000) Differential expression of cardiac titin isoforms and modulation of cellular stiffness. Circ Res 86, 59-67.

5 Hayashi C, Ono Y, Doi N, Kitamura F, Tagami M, Mineki R, Arai T, Taguchi H, Yanagida M, Hirner S et al. (2008) Multiple molecular interactions implicate the connectin/titin $\mathrm{N} 2 \mathrm{~A}$ region as a modulating scaffold for p94/calpain 3 activity in skeletal muscle. $J$ Biol Chem 283, 14801-14814.

6 Raynaud F, Fernandez E, Coulis G, Aubry L, Vignon X, Bleimling N, Gautel M, Benyamin Y and Ouali A (2005) Calpain 1-titin interactions concentrate calpain 1 in the Z-band edges and in the N2-line region within the skeletal myofibril. FEBS $J$ 272, 2578-2590.

7 Miller MK, Bang ML, Witt CC, Labeit D, Trombitas C, Watanabe K, Granzier H, McElhinny AS, Gregorio CC and Labeit S (2003) The muscle ankyrin repeat proteins: CARP, ankrd2/Arpp and DARP as a family of titin filament-based stress response molecules. $J$ Mol Biol 333, 951-964.

8 Lun AS, Chen J and Lange S (2014) Probing muscle ankyrin-repeat protein (MARP) structure and function. Anat Rec (Hoboken) 297, 1615-1629.

9 Garvey SM, Rajan C, Lerner AP, Frankel WN and Cox GA (2002) The muscular dystrophy with myositis (mdm) mouse mutation disrupts a skeletal musclespecific domain of titin. Genomics 79, 146-149.

10 Witt CC, Ono Y, Puschmann E, McNabb M, Wu Y, Gotthardt M, Witt SH, Haak M, Labeit D, Gregorio $\mathrm{CC}$ et al. (2004) Induction and myofibrillar targeting of CARP, and suppression of the Nkx2.5 pathway in the MDM mouse with impaired titin-based signaling. $J \mathrm{Mol}$ Biol 336, 145-154.

11 Bang ML, Gu Y, Dalton ND, Peterson KL, Chien KR and Chen J (2014) The muscle ankyrin repeat proteins CARP, Ankrd2, and DARP are not essential for normal cardiac development and function at basal conditions and in response to pressure overload. PLoS One 9, e93638. 
12 Zou Y, Evans S, Chen J, Kuo HC, Harvey RP and Chien KR (1997) CARP, a cardiac ankyrin repeat protein, is downstream in the Nk2-5 homeobox gene pathway. Development 124, 793-804.

13 Baumeister A, Arber S and Caroni P (1997) Accumulation of muscle ankyrin repeat protein transcript reveals local activation of primary myotube endcompartments during muscle morphogenesis. $J$ Cell Biol 139, 1231-1242.

14 Kemp TJ, Sadusky TJ, Saltisi F, Carey N, Moss J, Yang SY, Sassoon DA, Goldspink G and Coulton GR (2000) Identification of Ankrd2, a novel skeletal muscle gene coding for a stretch- responsive ankyrin-repeat protein. Genomics 66, 229-241.

15 Mikhailov AT and Torrado M (2008) The enigmatic role of the ankyrin repeat domain 1 gene in heart development and disease. Int J Dev Biol 52, 811-821.

16 Zolk O, Frohme M, Maurer A, Kluxen FW, Hentsch B, Zubakov D, Hoheisel JD, Zucker IH, Pepe S and Eschenhagen T (2002) Cardiac ankyrin repeat protein, a negative regulator of cardiac gene expression, is augmented in human heart failure. Biochem Biophys Res Commun 293, 1377-1382.

17 Nagueh SF, Shah G, Wu Y, Torre-Amione G, King NM, Lahmers S, Witt CC, Becker K, Labeit S and Granzier HL (2004) Altered titin expression, myocardial stiffness, and left ventricular function in patients with dilated cardiomyopathy. Circulation 110, 155-162.

18 Wei YJ, Cui CJ, Huang YX, Zhang XL, Zhang H and $\mathrm{Hu}$ SS (2009) Upregulated expression of cardiac ankyrin repeat protein in human failing hearts due to arrhythmogenic right ventricular cardiomyopathy. Eur $J$ Heart Fail 11, 559-566.

19 Bogomolovas J, Brohm K, Čelutkienė J, Balčiūnaitė G, Bironaitė D, Bukelskienė V, Daunoravičus D, Witt CC, Fielitz J, Grabauskienè V et al. (2015) Induction of Ankrd1 in dilated cardiomyopathy correlates with the heart failure progression. Biomed Res Int 2015, 273936.

20 Krüger M, Kötter S, Grützner A, Lang P, Andresen C, Redfield MM, Butt E, dos Remedios CG and Linke WA (2009) Protein kinase G modulates human myocardial passive stiffness by phosphorylation of the titin springs. Circ Res 104, 87-94.

21 Barash IA, Bang ML, Mathew L, Greaser ML, Chen J and Lieber RL (2007) Structural and regulatory roles of muscle ankyrin repeat protein family in skeletal muscle. Am J Physiol Cell Physiol 293, C218-C227.

22 Cheng WP, Wang BW, Lo HM and Shyu KG (2015) Mechanical stretch induces apoptosis regulator TRB3 in cultured cardiomyocytes and volume-overloaded heart. PLoS One 10, e 0123235.

23 Witt SH, Labeit D, Granzier H, Labeit S and Witt CC (2005) Dimerization of the cardiac ankyrin protein
CARP: implications for MARP titin-based signaling. $J$ Muscle Res Cell Motil 26, 401-408.

24 Jeyaseelan R, Poizat C, Baker RK, Abdishoo S, Isterabadi LB, Lyons GE and Kedes L (1997) A novel cardiac-restricted target for doxorubicin. CARP, a nuclear modulator of gene expression in cardiac progenitor cells and cardiomyocytes. J Biol Chem 272, 22800-22808.

25 Ishiguro N, Baba T, Ishida T, Takeuchi K, Osaki M, Araki N, Okada E, Takahashi S, Saito M, Watanabe M et al. (2002) Carp, a cardiac ankyrin-repeated protein, and its new homologue, Arpp, are differentially expressed in heart, skeletal muscle, and rhabdomyosarcomas. Am J Pathol 160, 1767-7178.

26 Johnson WC Jr (1999) Analyzing protein circular dichroism spectra for accurate secondary structures. Proteins 35, 307-312.

27 Konarev PV, Volkov VV, Sokolova AV, Koch MHJ and Svergun DI (2003) PRIMUS: a windows PC-based system for small-angle scattering data analysis. $J$ Appl Crystallogr 36, 1277-1282.

28 Rambo RP and Tainer JA (2013) Accurate assessment of mass, models and resolution by small-angle scattering. Nature 496, 477-481.

29 Franke D and Svergun DI (2009) DAMMIF, a program for rapid ab-initio shape determination in small-angle scattering. J Appl Crystallogr 42, 342346.

30 Volkov VV and Svergun DI (2003) Uniqueness of abinitio shape determination in small-angle scattering. $J$ Appl Crystallogr 36, 860-864.

31 Svergun DI (1999) Restoring low resolution structure of biological macromolecules from solution scattering using simulated annealing. Biophys J 76, 2879-2886.

32 Kabsch W (2010) XDS. Acta Crystallogr D Biol Crystallogr 66, 125-132.

33 McCoy AJ, Grosse-Kunstleve RW, Adams PD, Winn MD, Storoni LC and Read RJ (2007) Phaser crystallographic software. J Appl Crystallogr 40, 658-674.

34 Langer G, Cohen SX, Lamzin VS and Perrakis A (2008) Automated macromolecular model building for X-ray crystallography using ARP/wARP version 7. Nat Protoc 3, 1171-1179.

35 Emsley P, Lohkamp B, Scott WG and Cowtan K (2010) Features and development of Coot. Acta Crystallogr D Biol Crystallogr 66, 486-501.

36 Adams PD, Afonine PV, Bunkóczi G, Chen VB, Echols N, Headd JJ, Hung LW, Jain S, Kapral GJ, Grosse Kunstleve RW et al. (2011) The Phenix software for automated determination of macromolecular structures. Methods 55, 94-106.

37 McGuffin LJ, Bryson K and Jones DT (2000) The PSIPRED protein structure prediction server. Bioinformatics 16, 404-405. 
38 Drozdetskiy A, Cole C, Procter J and Barton GJ (2015) JPred4: a protein secondary structure prediction server. Nucleic Acids Res 43, W389-W394.

39 Green JR, Korenberg MJ and Aboul-Magd MO (2009) PCI-SS: MISO dynamic nonlinear protein secondary structure prediction. BMC Bioinformatics 10, 222.

40 Sedgwick SG and Smerdon SJ (1999) The ankyrin repeat: a diversity of interactions on a common structural framework. Trends Biochem Sci 24, 311-316.

41 Mosavi LK, Minor DL Jr and Peng ZY (2002) Consensus-derived structural determinants of the ankyrin repeat motif. Proc Natl Acad Sci USA 99, 16029-31604.

42 Roy A, Kucukural A and Zhang Y (2010) I-TASSER: a unified platform for automated protein structure and function prediction. Nat Protoc 5, 725-738.

43 Xue B, Dunbrack RL, Williams RW, Dunker AK and Uversky VN (2010) PONDR-FIT: a meta-predictor of intrinsically disordered amino acids. Biochim Biophys Acta 1804, 996-1010.

44 Linding R, Jensen LJ, Diella F, Bork P, Gibson TJ and Russell RB (2003) Protein disorder prediction: implications for structural proteomics. Structure 11, 1453-1459.

45 Linding R, Russell RB, Neduva V and Gibson TJ (2003) GlobPlot: exploring protein sequences for globularity and disorder. Nucleic Acids Res 31, 37013708.

46 Yachdav G, Kloppmann E, Kajan L, Hecht M, Goldberg T, Hamp T, Hönigschmid P, Schafferhans A, Roos M, Bernhofer M et al. (2014) PredictProtein-an open resource for online prediction of protein structural and functional features. Nucleic Acids Res $\mathbf{4 2}$ (Web Server issue), W337-W343.

47 Howarth JW, Ramisetti S, Nolan K, Sadayappan S and Rosevear PR (2012) Structural insight into unique cardiac myosin-binding protein-C motif: a partially folded domain. J Biol Chem 287, 8254-8262.

48 Marino M, Svergun D, Kreplak L, Konarev PV, Maco B, Labeit D and Mayans O (2005) Poly-Ig tandems from I-band titin share extended domain arrangements irrespective of the distinct features of their modular constituents. J Muscle Res Cell Motil 26, 355-365.

49 Rohs R, Etchebest C and Lavery R (1999) Unraveling proteins: a molecular mechanics study. Biophys $J \mathbf{7 6}$, 2760-2768.

50 Brockwell DJ, Paci E, Zinober RC, Beddard GS, Olmsted PD, Smith DA, Perham RN and Radford SE (2003) Pulling geometry defines the mechanical resistance of a beta-sheet protein. Nat Struct Biol 10, 731-737.
51 Schwaiger I, Sattler C, Hostetter DR and Rief M (2002) The myosin coiled-coil is a truly elastic protein structure. Nat Mater 1, 232-235.

52 Berkemeier F, Bertz M, Xiao S, Pinotsis N, Wilmanns M, Gräter F and Rief M (2011) Fast-folding alphahelices as reversible strain absorbers in the muscle protein myomesin. Proc Natl Acad Sci USA 108, 14139-14144.

53 Wolny M, Batchelor M, Knight PJ, Paci E, Dougan L and Peckham M (2014) Stable single $\alpha$-helices are constant force springs in proteins. J Biol Chem 289, 27825-27835.

54 Zacharchenzo T, von Castelmur E, Rigden DJ and Mayans O (2015) Structural advances on titin: towards an atomic understanding of multi-domain functions in myofilament mechanics and scaffolding. Biochem Soc Trans 43, 850-855.

55 Centner T, Yano J, Kimura E, McElhinny AS, Pelin K, Witt CC, Bang ML, Trombitas K, Granzier H, Gregorio CC et al. (2001) Identification of muscle specific ring finger proteins as potential regulators of the titin kinase domain. $J$ Mol Biol 306, 717-726.

56 Mrosek M, Labeit D, Witt S, Heerklotz H, von Castelmur E, Labeit S and Mayans O (2007) Molecular determinants for the recruitment of the ubiquitin-ligase MuRF-1 onto M-line titin. FASEB J 21, 1383-1392.

57 Bogomolovas J, Gasch A, Simkovic F, Rigden DJ, Labeit S and Mayans O (2014) Titin kinase is an inactive pseudokinase scaffold that supports MuRF1 recruitment to the sarcomeric M-line. Open Biol 4, 140041.

\section{Supporting information}

Additional Supporting Information may be found online in the supporting information tab for this article:

Data S1. Size exclusion chromatograms and SDS/ PAGE of recombinant samples of CARP and titin N2A domain components produced in this study.

Data S2. SEC-MALLS measurements of CARP and N2A components.

Data S3. Differential Scanning Fluorimetry measurements on CARP and Ig81.

Data S4. NMR analysis indicates that UN2A has a helically folded structure.

Data S5. Comparison of gel filtration chromatograms of UN2A and Ig81.

Data S6. CD spectrum of UN2A upon thermal incubation at $99{ }^{\circ} \mathrm{C}$ for $10 \mathrm{~min}$.

Data S7. Comparison of loop structure in Ig subtypes in titin. 